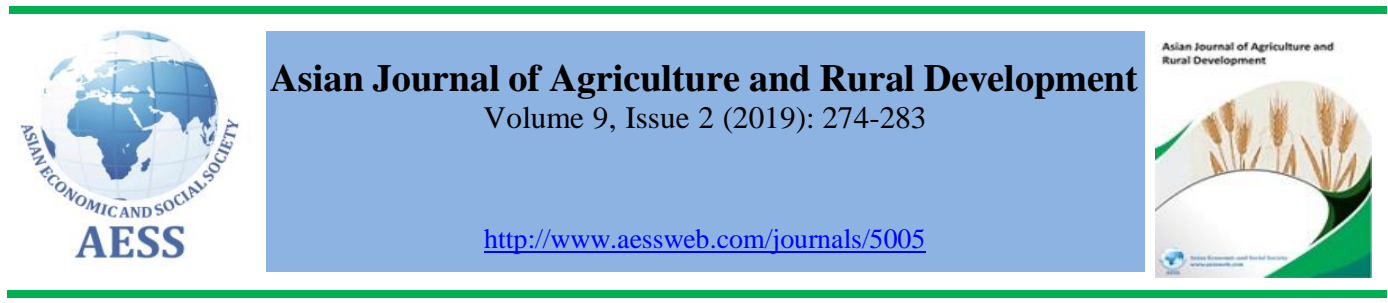

\title{
ADAPTING NEW TECHNOLOGIES OF EXPOSURE AND PROMOTION FOR AGRO-TOURISM ENTERPRISES WITH COMPARATIVE EVALUATIONS
}

\author{
Eleni \\ Dimitriadou $^{a}$, \\ Ioanna \\ Lamprouli $^{\text {b }}$, \\ Olga Iakovidou ${ }^{\mathrm{c}}$ \\ a PhD Candidate; Department of Agricultural Economics, \\ Aristotle University of Thessaloniki, Greece \\ ${ }^{\mathrm{b}}$ Agronomist; Aristotle University of Thessaloniki, Greece \\ c Emeritus Professor; Department of Agricultural Economics, \\ Aristotle University of Thessaloniki, Greece \\ \每imitri@agro.auth.gr (Corresponding author)
}

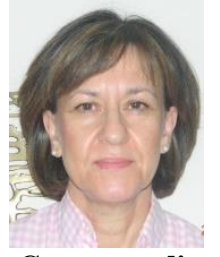

Corresponding author

\section{ARTICLE HISTORY: \\ Received: 11-Sep-2019 \\ Accepted: 22-Nov-2019 \\ Online Available: 16-Dec- \\ 2019}

\section{Keywords:}

Agrotourism enterprises,

Evaluation criteria,

Internet,

Promotion,

Websites

\begin{abstract}
As we are well aware that today the positive use of internet and shared websites comprise of various strong and prolific tools for business for the promotion of their products and services through world-wide advertisement, especially for small businesses in the rural areas. The paper at hand comprises of initial comparative study of the websites of the agro-tourism enterprises, which are located in Central Macedonia in Greece, with the very specific aim of investigating their adaptability plan and criteria towards the new technologies of exposure and promotion, since Central Macedonia is a larger and more developed region. Initially in 2010, 158 websites of agro-tourism enterprises were assessed, which were again surveyed in 2018. Through a census process, the data collecting method was adopted in this research, whereas the websites' assessment was conducted with the assistance of five criteria process, viz. content, interactivity, site attractiveness, promotional value and security, which were selected through literature review on the relevant subject. The evaluation confirmed our assumptions that the adaptability of new technologies for the agrotourism enterprises in Central Macedonia, Greece had improved, but the results of all evaluation criteria tend to show very low improvement, as seen in this century.
\end{abstract}

Contribution/ Originality

This study is the first effort to assess websites of agro-tourism enterprises of Central Macedonia in Greece. Additionally, it also presents the adaptation of new technologies in agro-tourism business using a unique data set collected for this study. The findings correspondingly provide amazing information on the current state and status of agro-tourism enterprises and their level of technological adaptation, as well as feasible incentives for the improvements in their adaptability.

DOI: 10.18488/journal.1005/2019.9.2/1005.2.274.283

ISSN (P): 2304-1455/ISSN (E):2224-4433

How to cite: Eleni Dimitriadou, Ioanna Lamprouli and Olga Iakovidou (2019). Adapting new technologies of exposure and promotion for agro-tourism enterprises with comparative evaluations. Asian Journal of Agriculture and Rural Development, 9(2), 274-283.

(C) 2019 Asian Economic and Social Society. All rights reserved. 


\section{INTRODUCTION}

Keeping in view the statement of Akpan et al. (2013) which mentioned that "Communication is central to human life", but nowadays, communication is mainly carried through internet, which is not only the means of exchanging and collecting information, but also a way for entrepreneurs access made easier for greater number of clients, in providing their relevant products and services to them (Andreopoulou et al., 2012), even if their establishment is impossibly accessible (Chung and Luc, 2017). Therefore, it is clearly indicated that internet comprises of a very strong tool for marketing (Andreopoulou et al., 2017), as small-size companies could size better and ample opportunities both to compete with others at international level (Pikkemaat and Zehrer, 2016) and to endure difficult environmental financial conditions (Maldonado-Guzmán et al., 2018). Investigations have shown that shared websites improve small-size enterprises' occupancy rates (Chung and Luc, 2016; Van and Tu, 2016). The incorporation of newer knowledge and feasible information into business operations enhances the technological capabilities; thus it contributes to the growth of business (Ukaejiofo, 2013) and also improves its performance (Maldonado-Guzmán et al, 2018). The number of agro-tourism enterprises who invest money to obtain new technologies has increased rapidly (Bajgier et al., 2017), keeping in view that in this way they would manage to extend their company. This new tool of promotion has attracted the interest of a great number of researchers, who have tried to study these websites, using different evaluation criteria (Law, 2007). But unfortunately, there are no common rules to be applied for the most appropriate criteria and what parameters should be included in every criterion.

Lituchy and Rail (2000) studied 114 small inns and beds and breakfasts, which were located in Canada and the United States of America. The study showed that 89,2\% of these enterprises had their own websites, with the specific aim of increasing their customers' base. However, their websites were not characterized by multilingual capabilities, converting them to some extent, into unattractive spots for foreign tourists. On the other hand, results of 193 websites of small and medium sized hotels in Malaysia showed that 65,3\% catered to English speakers, while 69,9\% provided the opportunity to their users to make online reservations, whereas online cancellation, confirmation and payments were also made available therein, while only 45,0\% of websites informed users about privacy and security policy regarding reservations (Ayob, 2016). On the contrary, opposite results were reported by 29 websites of agro-tourism enterprises in Crete, as only a few websites had online reservations, payment system and registration as members. In other words, internet adoption was in its first steps and it was essential for them to use e-commerce in order to become more competitive (Andreopoulou et al., 2017).

Similarly, Król (2017) found that out of a total of 400 agro-tourism firms in four countries (Poland, Slovakia, Czech Republic and Hungary) only 145 had a personal website, which enhanced the passive attitude of potential customers. This could be attributed to the fact that customers could neither be informed about the prices, nor of the high quality of their services, and were characterized by poor content, while at the same time no update was made on the date on which the web pages were modified, causing severe insecurity for the consumers.

Beldona and Cai (2006) evaluated 50 websites of agro-tourism enterprises in the United States, using only three criteria; viz. content, interactivity and promotional value. The percentage of at least $64,0 \%$ of websites was characterized by high level of content, providing the information for some aspects like, accommodation, facilities, attractions, and transportation. 19,0\% of the websites was ranked in high level of interactivity, such as online reservation, search tool and site for membership were some parameters, which helped users to obtain a more active behavior, while $17,0 \%$ of the enterprises presented high promotional value, sustaining the users' interests because they had online offers, newsletters and e-cards. In other words, these websites should have to be improved for users' proper control and set their decision to influence and increase accordingly. 
Moreover, 20 websites of the Indiana Bed and Breakfast Association were examined, using four criteria, namely, user friendliness, site attractiveness, marketing effectiveness and technical aspects, which are not included in our research. Due to the easy users' navigation, 63,7\% of websites were characterized by friendliness; a homepage button, site maps, search tool, limited scrolling and contact details were shown to be some of the recorded parameters, while $88,5 \%$ of those were evaluated by site attractiveness, referring a hospitable company. These websites had a good quality of pictures, background colors and text readability. Moreover, 40,2\% were ranked in terms of marketing effectiveness, owing to the existence of some parameters, such as house and room photos, virtual tours, calendars of local events, outdoor activities and awards, which an entrepreneur may have won by converting a stimulated experience to a real one (Kline et al., 2005). Different results were even recorded by websites of small-size hotels in Scotland, whose entrepreneurs did not take the advantages of their function; and as a result, these websites consisted of an online brochure presentation (Bingley et al., 2009).

In Poland, small agro-tourism farms used websites in order to promote their business as well as rural tourism. A percentage of $67,4 \%$ was characterized by insufficient content, as information about their firms and services was not provided therein. Mistrust was established and sales functions were not performed well, so these websites were considered nothing else rather than "abandoned" websites (Król, 2019).

This paper could be considered as a revised and expanded version of an earlier presentation entitled 'The adaptability of the agro-tourism enterprises to the new technologies of exposure and promotion. A comparative evaluation", presented at the $15^{\text {th }}$ National Conference Agricultural Economics, Thessaloniki in Greece, on $1^{\text {st }}$ and $2^{\text {nd }}$ November 2018. Additionally, the present paper contributes to the relevant literature, being established as the first study assessing the adaptability of new technologies for the exposure and promotion of agro-tourism business in Central Macedonia, using special criteria, like content of websites, interactivity, attractiveness, promotional value and security. From a managerial and practitioner perspective, the present study also informs about the level of agro-tourism business adaptability of the new technologies and motivations for future planning.

\section{MATERIALS AND METHODS}

The research was carried out in Central Macedonia in Greece due to the significant development of agrotourism. This study consisted of two stages. The first got off the ground in 2010, as a part of the graduate dissertation (see Lamprouli, 2010) and the second stage materialized in 2018, following the same process of evaluation. The number of agrotourism enterprises was registered based on data of the Development Agencies and Chambers of seven Prefectures in Central Macedonia (Chalkidiki, Imathia, Kilkis, Pella, Pieria, Serres, Thessaloniki) and after their websites were identified on the internet.

The evaluation of websites of agrotourism enterprises was based on global bibliography (Hashim et al., 2007; Baloglu and Pechan, 2006; Beldona and Cai, 2006; Kline et al., 2005; Chiang, 2003; Doolin et al., 2002; Feng et al., 2002; Wan, 2002), including five criteria; content, interactivity, site attractiveness, promotional value and security. The criterion of content included 18 parameters, 10 of them were related to the enterprise itself and the others to the region of establishment. The criterion of interactivity consisted of 8 parameters and the criterion of site attractiveness 12 parameters, while the criteria of promotional value and security had 3 and 6 parameters respectively. Every parameter of the evaluation criteria was graded with 10 points. According to the number of parameters every criterion had, the website was classified into low, medium and high level of evaluation. Specifically, websites were ranked in the low level of content as long as they 
had up to 60 points, in medium level, providing that they had 61-120 points and at a high level if they had $121-180$ points. The ranges of the evaluating criteria are listed below.

Table 1: Classification of five evaluation criteria

\begin{tabular}{lccc}
\hline Criteria & Low & Medium & High \\
\hline Content & $0-60$ & $61-120$ & $121-180$ \\
Interactivity & $0-26,67$ & $26,68-53,34$ & $53,35-80$ \\
Site attractiveness & $0-40$ & $41-80$ & $81-120$ \\
Promotional value & $0-10$ & $11-20$ & $21-30$ \\
Security & $0-20$ & $21-40$ & $41-60$ \\
\hline
\end{tabular}

Source: Authors' own compilations

The parameters of all criteria were equal, as the agrotourism product, in order to be fulfilled, should have parameters not only for the enterprise itself, its products and its services, but also for the sights and attractions, which were close to it and for the available activities, which tourists could do after their visit.

In this research, the method of census was selected, since this will enable to the generalization of the results, even if the data are heterogeneous (Harisis and Kiohos, 1997). The codification of data was carried out through the statistical package for the social sciences SPSS, version 18 (year 2010) and 24 (year 2018).

\section{RESULTS}

In Central Macedonia, the total number of agrotourism enterprises in 2010 was 327; 158 of those had their own website. After 8 years, this number decreased to 131 websites; as 5 enterprises closed and 22 of them have operated, in an alternative and economical way of promotion, which is less expensive than their own ones, such as local websites, cooperative platforms or Facebook, which is the most popular way of financial promotion.

The criterion of content included parameters both for the enterprise itself and for the region of establishment. In the first case (Table 2), both in 2010 and 2018, the interest of entrepreneurs focused on room facilities and general facilities of the company, as the percentage of websites increased from $85,4 \%$ to $87,8 \%$ and from $67,7 \%$ to $86,3 \%$ respectively. An impressive rise appeared in two parameters; information about products and services and description of enterprise, as their percentages had almost doubled after 8 years, describing the properties and characteristics of lodgings. 29 websites of agro-tourism enterprises in Crete showed similar interest, as they informed their clients for the offered products and services in great detail (Andreopoulou et al., 2017). In contrast small agritourism farms in Poland were characterized by poor content, due to the lack of sufficient information (Król, 2019). Moreover, both years, information about the distance between the company and nearby villages and cities was given to users, as entrepreneurs believed that these elements would have a positive influence on users' final decision. On the other hand, the majority of websites in 2010 informed users about the number of rooms the company had, something which also recorded in 2018 reduced by almost 10\%. Moreover, the parameter of operating period was slightly reduced after 8 years; in contrast, the history of the foundation and the prices of products and services exhibited a small increase. In both years, a negligible number of websites provided information regarding prizes the enterprises won because the owners either believed it was meaningless or they had not received any honors in the past. 
Table 2: Evaluation based on the criterion of content, related to the enterprise itself from 2010-2018

\begin{tabular}{lcc}
\hline $\begin{array}{l}\text { The criterion of content which } \\
\text { was related to the enterprise itself }(\boldsymbol{\%})\end{array}$ & $\mathbf{2 0 1 0}$ & $\mathbf{2 0 1 8}$ \\
\hline History of foundation & 9,5 & 16,8 \\
Information about facilities & 67,7 & 86,3 \\
Description of enterprise & 38,6 & 88,5 \\
Information about products and services & 43,0 & 90,8 \\
Number of rooms & 77,2 & 66,4 \\
Room facilities & 85,4 & 87,8 \\
Period of operation & 28,5 & 18,3 \\
Prizes & 0,6 & 10,7 \\
Prices of services & 17,7 & 22,9 \\
Distance from surroundings & 74,7 & 72,5 \\
\hline
\end{tabular}

Note: The total number of agrotourism websites in 2010 was 158 and in 2018 was 131

Source: Authors' own compilations

In the second case, the years 2010 and 2018 did not present significant differences (Table 3). Specifically, $48,1 \%$ of websites of agrotourism enterprises in 2010 referred to the sights, which were close to them, while in $2018,69,5 \%$ gave information about these attractions. Also, outdoor activities were proposed by 53,8\% of websites in 2010 and $58,0 \%$ of them in 2018 . Users had the chance to understand with the aim of this information if an agrotourism enterprise provided a complete product. Another important element in 2010 and 2018 was the existence of area maps, through which users spotted enterprises geographically, as their percentages went up from $65,8 \%$ to $78,5 \%$. On the other hand, entrepreneurs believed that alternative means of transport (bus, train, except cars), local events, a festival calendar, information for weather conditions and local news could not attract tourists, so these parameters were of secondary importance for them.

Table 3: Evaluation based on the criterion of content, related to the location from 2010-2018

\begin{tabular}{lcc}
\hline The criterion of content which was & $\mathbf{2 0 1 0}$ & $\mathbf{2 0 1 8}$ \\
Related to the region of establishment $(\boldsymbol{\%})$ & 48,1 & 69,5 \\
\hline Sights and attractions & 53,8 & 58,0 \\
Outdoor activities (trekking, climbing) & 6,3 & 13,0 \\
Means of transport & 13,9 & 13,0 \\
Local events & 7,0 & 6,9 \\
Calendar of festivals & 65,8 & 78,5 \\
Area Maps & 15,8 & 11,5 \\
Weather forecast & 3,8 & 0,8 \\
Local news & & \\
\hline
\end{tabular}

Note: The total number of agrotourism websites in 2010 was 158 and in 2018 was 131

Source: Authors' own compilations

Concerning the criterion of interactivity (Table 4), all websites of agrotourism enterprises in 2010 and 2018 gave contact details, while the percentage of online contact form had almost duplicated, as from $39,2 \%$ in 2010 reached to $67,9 \%$ in 2018 . Conversation communities (chat rooms, forums) remained a less popular way of communication, as they increased went up from 1,9\% in 2010 to $9,9 \%$ in 2018 . The users' registration as members and their registration for sending newsletters did not display significant differences between the two years. The site search tools and the online guest books appeared to have similar level of increase. The last parameter that was assessed, was the virtual tool, whose percentage in 2010 was $7,0 \%$, while in 2018 increased to $34,4 \%$. 
Table 4: Evaluation based on the criterion of interactivity from 2010-2018

\begin{tabular}{lcc}
\hline The criterion of interactivity (\%) & $\mathbf{2 0 1 0}$ & $\mathbf{2 0 1 8}$ \\
\hline Site search tool & 4,4 & 16,2 \\
User' registration as a member & 5,7 & 12,2 \\
Contact information & 100 & 100 \\
Online contact form & 39,2 & 67,9 \\
Community conversation & 1,9 & 9,9 \\
User' registration for sending newsletters & 1,9 & 13,7 \\
Virtual tour & 7,0 & 34,4 \\
Online guest book & 7,0 & 18,3 \\
\hline
\end{tabular}

Note: The total number of agrotourism enterprises' websites in 2010 was 158 and in 2018 was 131

Source: Authors' own compilations

The criterion of site attractiveness (Table 5) examined the existence of room and hotel pictures on websites of agrotourism enterprises in 2010 and 2018, and the results do not support significant differences. The majority of these photographs could be characterized by high quality, while background colors exhibited a small reduction by $9,8 \%$, making them less attractive. Similar results were supported by the websites of the Indiana Bed and Breakfast Association, characterized as a hospitable company (Kline et al., 2005). Almost half of websites were multilingual in 2010, while this percentage reached $71,4 \%$ in 2018 , giving the opportunity to more foreign users to visit them and understand their content. The same chance was given to potential clients at $65,3 \%$ of websites of small and medium sized hotels in Malaysia (Ayob, 2016). 3,8\% of websites in 2010 had a site map, while in 2018 this percentage reached the 30,5\%, preventing users to confuse and abandon these websites. To this destination, the increased percentage of accessible information through various ways and points assisted. In both years, a very small number of websites included links which directed users to other proposed websites for other enterprises in their area, such as café bars, restaurants. Moreover, URL links which provided information about local society (municipalities, museums) were reduced from $29,7 \%$ to $13 \%$ in 2018 . In both years, the majority of websites did not have videos, audio or music, as it was believed that these tools would not attract clients.

Table 5: Evaluation based on the criterion of site attractiveness from 2010-2018

\begin{tabular}{lcc}
\hline The criterion of site attractiveness (\%) & $\mathbf{2 0 1 0}$ & $\mathbf{2 0 1 8}$ \\
\hline Room photos & 94,9 & 96,9 \\
Hotel photos & 91,1 & 96,9 \\
Good quality of photos & 86,7 & 90,8 \\
Background colors & 96,8 & 87,0 \\
Links to websites of other enterprises & 3,2 & 4,6 \\
Links to websites of local services & 29,7 & 13,0 \\
Site map & 3,8 & 30,5 \\
Videos & 19,0 & 26,7 \\
Audio & 7,6 & 3,1 \\
Music & 21,5 & 2,3 \\
Multilingual website & 46,8 & 71,4 \\
Accessible information through various ways and points & 22,2 & 38,9 \\
\hline
\end{tabular}

Note: The total number of agrotourism enterprises' websites in 2010 was 158 and in 2018 was 131

Source: Source: Authors' own compilations

Regarding the criterion of promotional value results do not indicate any significant differences (Table 6). Specifically, in 2010, 1,9\% of websites sent emails to users, informing them for an enterprise itself and the nearby area while this percentage increased to $13,7 \%$ in 2018 . Between the 
two years, negligible differences were recorded by sending e-cards to users, while online offers showed a small reduction, as the percentage decreased from $19,6 \%$ to $12,2 \%$. Insignificant results were also presented by websites of agrotourism enterprises in the United States, which did not control and influence the users' decisions in these promotional ways (Beldona and Cai, 2006).

Table 6: Evaluation based on the criterion of promotional value from 2010-2018

\begin{tabular}{lcc}
\hline The criterion of promotional value (\%) & $\mathbf{2 0 1 0}$ & $\mathbf{2 0 1 8}$ \\
\hline Sending e-cards to users & 0,6 & 1,5 \\
Email notification & 1,9 & 13,7 \\
Online offers & 19,6 & 12,2 \\
\hline
\end{tabular}

Note: The total number of agrotourism enterprises' websites in 2010 was 158 and in 2018 was 131

Source: Authors' own compilations

The results of the criterion of security did improve after 8 years, however, it remained very low (Table 7). Specifically, in 2018, half of websites gave the ability to potential clients to make online reservation, compared to $27,8 \%$ of websites in 2010 , while online cancellation and online payment exhibited a very small rise. Similar results were exported by the websites of agrotourism enterprises in Crete, as only a few had adopted e-commerce (online reservation and payment system) so as to become economically strong (Andreopoulou et al., 2017).The results of security of personal data and terms and conditions of reservation remained very disappointing, since their increase was insignificant. The last update was stated by $11,4 \%$ of websites in 2010 and $14,6 \%$ in 2018 , increasing users' insecurity, something which is confirmed by the websites of agrotourism farms in Poland, Slovakia, Czech Republic and Hungary (Król, 2017) as well by the websites of small agritourism farms in Poland, which consisted of historical sites and were called as "abandoned" websites (Król, 2019).

Table 7: Evaluation based on the criterion of security from 2010-2018

\begin{tabular}{lcc}
\hline The criterion of security (\%) & $\mathbf{2 0 1 0}$ & $\mathbf{2 0 1 8}$ \\
\hline Online reservation & 27,8 & 51,1 \\
Online cancellation & 0,6 & 10,0 \\
Online payment & 1,9 & 12,2 \\
Terms and conditions/reservation policy & 8,9 & 19,8 \\
Security of personal data & 3,2 & 11,5 \\
Date of last update & 11,4 & 14,6 \\
\hline
\end{tabular}

Note: The total number of agrotourism enterprises' websites in 2010 was 158 and in 2018 was 131

Source: Authors' own compilations

Based on the criterion of content, all websites were classified between low and medium level, while none of them was ranked in high level during 2010. These results differentiated after 8 years, most of the websites was characterized by medium level of content and for the first time a small number of websites appeared in high level. Concerning the criterion of interactivity, the largest number of websites was ranked in low level of evaluation in 2010, while in 2018 almost all websites were rated between low and medium level. Regarding the criterion of site attractiveness, an improvement was evident after 8 years, due to the increase of medium level. The percentages of the criteria of promotional value and security were discouraging, because almost all websites were rated in low level of evaluation, without presenting important differences in 2018. Noteworthy is the fact that none of the websites were marked in high level of promotional value in 2018 and in high level of security in 2010 (Table 8). 
Table 8: Comparison of websites evaluation in levels from 2010-2018

\begin{tabular}{lcccccc}
\hline $\begin{array}{l}\text { Evaluation } \\
\text { criteria }\end{array}$ & \multicolumn{3}{c}{$\mathbf{2 0 1 0}$} & \multicolumn{3}{c}{$\mathbf{2 0 1 8}$} \\
\cline { 2 - 7 } Level (\%) & Low & Medium & High & Low & Medium & High \\
\hline Content & 48,1 & 51,9 & 0,0 & 21,4 & 77,8 & 0,8 \\
Interactivity & 88,0 & 11,4 & 0,6 & 50,4 & 45,8 & 3,8 \\
Site attractiveness & 34,8 & 60,1 & 5,1 & 17,6 & 80,9 & 1,5 \\
Promotional value & 98,8 & 0,6 & 0,6 & 95,4 & 4,6 & 0,0 \\
Security & 97,5 & 2,5 & 0,0 & 82,4 & 12,2 & 5,4 \\
\hline
\end{tabular}

Source: Authors' own compilations

The majority of websites gives to potential clients more information now than 8 years before, strengthening their enterprise image. However, users are obligated to communicate with owners in order to ask for more details (working seasons, prices of products and services or means of transport). During both years, websites of agrotourism enterprises presented a complete agrotourism product, as information for the enterprise itself, its products and services, sights and outdoor activities were provided. The criterion of interactivity presents a relative improvement in 2018, converting the passive users' attitude to more active and differentiating websites from traditional types of advertisements. On the other hand, most websites have improved their appearance, so they attract more users and convert them to clients easier, as an image of an equally attractive business created, remains in users' memory. Opposite results have been extracted by the criteria of promotional value and security, which continue to be very low after 8 years. Agrotourism entrepreneurs are not interested in maintaining their communication with clients by sending newsletters and e-cards regularly to remind them of their existence, provide motivation to users (online offers) and repeat their visit to their websites. Also, a guarantee for protection of users' personal data and a statement of the last update are not given, making the validity of this information doubtful. In this way, a sense of insecurity is cultivated and online customer relationships are discouraged.

\section{CONCLUSIONS}

In this survey, an assessment of agro-tourism enterprises' websites in Central Macedonia was conducted with the vast perspective of their technical adaptation during the years 2010 to 2018 . Five criteria, namely, content, interactivity, site attractiveness, promotional value, security, were used for the websites' evaluation, based simply on literature review. The findings showed that the agro-tourism enterprises in Central Macedonia have increased their adaptability towards new technologies. However still there is a need for a greater improvement and support policy, since their level is relatively quite low.

Funding: This study received no specific financial support.

Competing Interests: The authors declared that they have no conflict of interests.

Contributors/Acknowledgement: We would like to thank the managers of Development Agencies and Chambers of Seven Prefectures in Central Macedonia in Greece, as their assistance was precious.

Views and opinions expressed in this study are the views and opinions of the authors, Asian Journal of Agriculture and Rural Development shall not be responsible or answerable for any loss, damage or liability etc. caused in relation to/arising out of the use of the content.

\section{References}

Akpan, U., Akwaowo, E., \& Senam, N. (2013). Uses and gratifications of social networking. International Journal of Asian Social Science, 3(2),353-369. 
Andreopoulou, Z., Lemonakis, C., Koliouska, C., \& Zopounidis, C. (2017). Internet and agrotourism sector for regional development in Crete: A multicriteria ranking. International Journal Information and Decision Sciences, 9(2), 116-127. doi.org/10.1504/ijids.2017.10005872.

Andreopoulou, Z., Koliouska, C., \& Tsekouropoulos, G. (2012). Strategic planning and decision support in small-medium wood enterprises using database technology. Journal of Agricultural Informatics, 3(1), 36-45. doi.org/10.17700/jai.2012.3.1.85.

Ayob, F. (2016). Evaluating websites of small-and-medium-sized-hotels (SMHs): A stages model of e-commerce websites adoption for Malaysian Hotels. Journal of Hotel and Business Management, 5(2), 149-154. doi.org/10.4172/2169-0286.1000149.

Bajgier, K. M., Tracz, M., \& Uliszak, R. (2017). Modeling the state of agritourism in the Malopolska region of Poland. Tourism Geographies, 19(3), 502-524. doi.org/10.4172/21690286.1000149 .

Baloglu, S., \& Pekcan, Y. (2006). The website design and internet site marketing practices of upscale and luxury hotels in Turkey. Tourism Management, 27(1), 171-176. doi.org/10.1016/j.tourman.2004.07.003.

Beldona, S., \& Cai, L. (2006). An exploratory evaluation of rural tourism websites. Journal of Convention and Event Tourism, 8(1), 69-80. doi.org/10.1300/j452v08n01_04.

Bingley, S., Sellitto, C., \& Burgess, S. (2009). The importance of third party websites: A study of small accommodation providers in Australia. Proceedings of the $4^{\text {th }}$ International Scientific Conference: Planning for the future-Learning from the past. Developments in Travel, Tourism Hospitality, 3-5 April 2009, Rhodes Island, Greece.

Chiang, L. C. (2003). Effectiveness of the hotel websites in Singapore: A perspective from business to business (B2B) organizations. Asia Pacific Journal of Tourism Research, 8(2), 38-47. doi.org/10.1080/10941660308725467.

Chung, N. V., \& Luc, T. T. (2016). Impact of e-commerce website on small tourism enterprises in Quang Binh, Vietnam. Journal of Asian Business Strategy, 6(10), 221-225. 10.18488/journal.1006/2016.6.10/1006.10.221.225.

Doolin, B., Burgess, L., \& Cooper, J. (2002). Evaluating the use of the web for tourism marketing: A case study from New Zealand. Tourism Management, 23(5), 557-561.

Feng, R., Morrison, A. M., \& Ismail, J. A. (2002). East versus west: A comparison of online destination marketing in China and the USA. Journal of Vacation Marketing, 10(1), 43-56. doi.org/10.1177/135676670301000105.

Harisis, K., \& Kioxos, P. (1997). Theory of sampling and implication. Athens, Greece: Interbooks.

Hashim, N. H., Murphy, J., \& Law, R. (2007). A review of hospitality website design frameworks. In: Information and Communication Technologies in Tourism, edited by Sigala M., Mich L. and Murphy J. (Springer, Vienna). 219-230.

Kline, S. F., Morrison, A. M., \& John, A. S. (2005). Exploring bed and breakfast websites. Journal of Travel and Tourism Marketing, 17(2), 253-267. doi.org/10.1300/j073v17n02_19.

Król, K. (2017). Promoting of agro tourism on the internet - a lesson from the vise grad group countries. Journal of Agribusiness and Rural Development, 4(46), 805-813. doi.org/10.18778/0867-5856.27.1.11.

Król, K. (2019). Forgetten agritourism: abandoned websites in the promotion of rural tourism in Poland. Journal of Hospitality and Tourism Technology, 10(3), 431-422. doi.org/10.1108/jhtt09-2018-0092.

Lamprouli, I. (2010). The promotion of agro tourism enterprises via internet. (Master's thesis). Department of Agrotourism Economics, Faculty of Agriculture, Aristotle University of Thessaloniki, Greece.

Law, R. (2007). A Fuzzy multiple criteria decision - making model for evaluating travel websites. Asia Pacific Journal of Tourism Research, 12(2), 147-159. doi.org/10.1080/10941660701243372. 
Lituchy, T. R., \& Rail, A. (2000). Bed and breakfasts, small inns and the internet: The impact of technology on the globalization of small businesses. Journal of International Marketing, 8(2), 86-97. doi.org/10.1509/jimk.8.2.86.19625.

Maldonado-Guzmán, G., Marín-Aguilar, J. T., \& García-Vidales, M. (2018). Innovation and Performance in Latin-American small family firms. Asian Economic and Financial Review, 8(7), 986-998. doi.org/10.18488/journal.aefr.2018.87.986.998.

Pikkemaat, B., \& Zehrer, A. (2016). Innovation and service experiences in small tourism family firms. International Journal of Culture, Tourism and Hospitality Research, 10(4), 343-360. doi.org/10.1108/ijcthr-06-2016-0064.

Ukaejiofo, R. U. (2013). Technological innovation capacity: impact factors in national agricultural research organizations in Nigeria. Asian Journal of Agriculture and Rural Development, 3(4), 163-168.

Van, C. N., \& Tu, L. T. (2016). Impact of e-commerce website on small tourism enterprises in Quang Binh, Vietnam. Journal of Asian Business Strategy, 6(10), 221-225. 10.18488/journal.1006/2016.6.10/1006.10.221.225.

Wan, C. S. (2002). The websites of international tourist hotels and tour wholesalers in Taiwan. Tourism Management, 23(2), 155-160. doi.org/10.1016/s0261-5177(01)00048-6. 